\title{
CALCULATION OF TWO-LAYER BILLET OF SPHERICAL BOTTOMS FOR HIGH-PRESSURE VESSELS
}

\author{
A.S. PROKOFIEV ${ }^{1}$, R.S. GUBATYUK ${ }^{1}$, A.F. MUZHICHENKO ${ }^{1}$ and V.N. BARANOVSKY ${ }^{2}$ \\ ${ }^{1}$ E.O. Paton Electric Welding Institute, NASU \\ 11 Kazimir Malevich Str., 03680, Kiev, Ukraine. E-mail: office@paton.kiev.ua \\ ${ }^{2}$ Ternopol Ivan Puluj National Technical University, Ministry of Education and Science of Ukraine \\ 56 Russkaya Str., 46001, Ternopol, Ukraine
}

\begin{abstract}
The article presents the materials of calculations of circumferential stresses and radial displacements in the wall of two-layer spherical bottom. Three models of bottoms were considered, where different combinations of materials for manufacture of shell layers are used. The rational layer thicknesses, circumferential stresses and radial displacements were determined, which formed in them in the ranges of elastic deformations at different combinations of materials of shell layers. The determination of circumferential stresses was carried out by calculation method according to the analytical dependences and by the method of computer simulation. The application of material with higher strength properties in manufacture of the outer shell leads to the effective loading of their common wall, reduction in its thickness and, correspondingly, increase in its inner stresses and, eventually, in the rational loading. 10 Ref., 4 Tables, 3 Figures.
\end{abstract}

Keywords : welded structure, two-layer shell, spherical bottom, calculation model, stresses, deformations, welded vessels

The application of two-layer and, in perspective, multilayer materials for manufacture of shell welded structure allows obtaining the certain advantages in most cases. These advantages are increase in such indicators as wear resistance, corrosion resistance, increased resistance to cyclic loads as well as the ability to create a high resistance to fatigue fracture. The safe operation of such welded shell structure consists in the achievement of rational distribution of stresses in its walls during application of the operational load. The preliminary stressed structures are also used.

For two-layer cylindrical shell structures the joints with tension are applied that allows reducing the thickness of the common wall and obtaining the rational distribution of stresses, which are formed in the common wall during application of the operation load. Also the application of the material, resistant to cyclic loads in a two-layer shell structure, allows redistributing the basic cyclic load, applied to the entire welded structure, to the layer where the given material is applied and, thus, unloading the layers, which have a reduced resistance to cyclic loading, but have other operational or technological properties (for example, corrosion resistance).

To meet the requirements to corrosion resistance in welded structures of the type of containers, vessels, cylinders, the application of protective coatings on the inner surface or manufacture of a two-layer body is possible, where the material of the inner layer is manufactured of metal having increased corrosion resis- tance. It is known that two-layer sheet bimetallic materials can be produced using the method of explosion welding $[1,2]$. Also, the double-layer sheet bimetallic materials can be produced using the method of induction press braze-welding [3-5].

The two-layer cylindrical bodies can be also produced by coaxial fitting-up of the heated outer shell on the inner one, which provides tightness. In this way the double-layer cylindrical bodies can be also produced by the method of thermal shrinkage of the outer shell to the inner one, carrying out induction heating by a gradual movement of the coaxially assembled inner and outer shells. The given technology has a number of advantages, consisting in the fact that the induction heating is significantly cheaper, it does not influence the surface of heating, as compared to gas heating, and it can be realized in any, including protective atmosphere.

In work [6] three models of cylindrical bodies of the same type were considered, operating under pressure, where the wall of the cylindrical body represents a two-layer shell (Figure 1). The thickness of the inner thin-walled shell (ratio of diameter to the wall thickness is 10 and more) for all three models is constant. In the calculation models the outer shell is fitted to the inner shell with a minimum tightness, close to zero, while its inner diameter matches the outer diameter of the shell, and its outer diameter is calculated basing on the strength properties for the each applied material. For all three models of two-layer cylindrical 


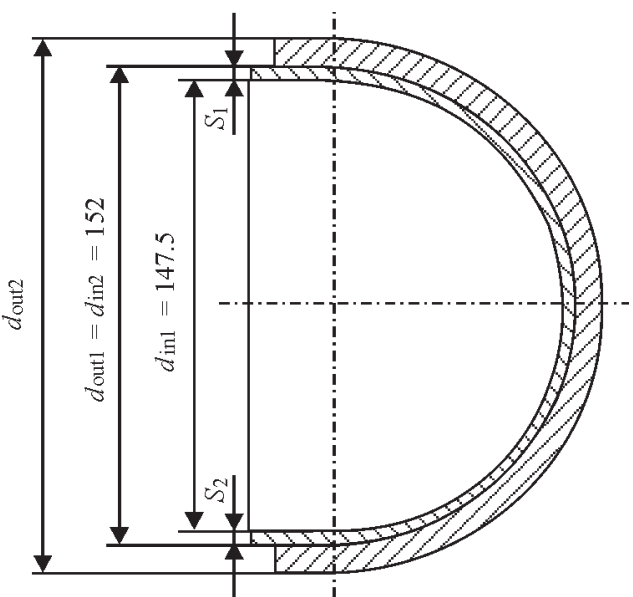

Figure 1. Design of spherical bottom [6]

bodies of vessels, the calculated values of wall thicknesses of the outer shell and the common wall and the stresses formed in the shells and in the common wall, were presented in work [6]. This article presents calculations of models of three similar-type two-layer welded structures of spherical bottoms for welded vessels, operating under pressure, moreover, in all the models the inner thin-walled shell of spherical bottom has the same geometric dimensions, which coincide with abutting dimensions for all three models of the inner thin-walled shell of the cylindrical body.

To determine the stresses, formed in the shell wall, the welded structure of the vessel was considered, operating under pressure, where the cylindrical wall of the body and the spherical bottoms were manufactured of the two-layer material. Three similar-type welded structures of vessels (Table 1) are calculation models, where for the purpose of choosing the optimal parameters the combination of different grades of steels for the inner and outer layer is used. Accordingly, the strength characteristics of the steel grades, used for the each layer of the shell, were laid to the calculation models. The subject of the investigation was the stresses formed in the layers of the two-layer spherical bottom and in the common two-layer wall, as well as the determination of the amount of deformation during application of operating pressure for three models.

The thicknesses of the walls of outer shells of the spherical bottoms $S_{2}$ and the cylindrical bodies $S_{2 \mathrm{~b}}$ and, relatively, the thicknesses of the common walls of the bottom $S$ and the cylindrical bodies $S_{\mathrm{b}}$ in all three models may not coincide. However, it allows producing the circumferential weld, joining the cylindrical body with the spherical bottom. At the same time, the wall thicknesses and matched diameters of the inner shells for all three models are provided and the presence of some different thicknesses of walls of the outer shells (up to 15-20\% of the common thickness of the outer shell wall) is observed. It allows, as a result, designing and forming three similar-type models of welded structures: of a welded vessel with a double-layered cylindrical body and a two-layer spherical bottom on the basis of the obtained calculation data. Moreover, in each model the materials of the steel grades of the body and bottom layers coincide, and between the models of cylinders there is no matching in the materials of the two-layer shells. The calculations on the choice of geometric parameters of the similar-type two-layer structures of the spherical bottoms for the vessels, operating under pressure, were carried out according to the known methods [7-9]. The combination of different steel grades for the inner and outer shells in three models of spherical bottom was selected in accordance with work [6] for three models of a two-layer cylindrical body of the welded vessel. At the same time, the following conditions were observed:

- calculations were carried out taking into account the same inner operating pressure $P_{\text {op }}=20 \mathrm{MPa}$ and the same geometrical dimensions of the inner shell wall of the bottom $\left(d_{\text {in } 1}=47.5 \mathrm{~mm} ; d_{\text {out } 1}=152 \mathrm{~mm}\right.$; wall thickness of the inner shell of the spherical bottom is constant $S_{1}=2.25 \mathrm{~mm}$ ) for all three models of welded vessels;

- inner diameter of the spherical outer shell corresponds to the outer diameter of the wall of the inner spherical shell for all three types of welded vessels and is constant $\left(d_{\text {out } 1}=d_{\text {in2 }}=152 \mathrm{~mm}\right)$;

- dimensions of the wall of the spherical outer shell $\left(d_{\text {out }}, S_{2}\right)$ were calculated basing on the stresses formed in it (the outer shell) and the strength characteristics of the used steel grade;

- in the structure of spherical bottom from the calculated thicknesses of the common wall of the bottom $S$ its minimum value was taken;

- stresses in the separate shells of the spherical bottom $\sigma_{1}, \sigma_{2}$, as well as the total stresses in the common wall of the bottom $\sigma$ were determined without taking the tightness into account;

- calculation was carried out according to the acting standard documents and provisions of work [7], moreover, the operating operational pressure of the model of the welded vessel was calculated (at safety

Table 1. Combination of material and ratio of thicknesses of shell walls of spherical bottom for the models

\begin{tabular}{|c|c|c|}
\hline Model number & Materials of inner $S_{1}$ and outer shell $S_{2}$, respectively & $S_{1} /\left(S_{2}+C\right)$ \\
\hline 1 & Steel 08kp + high-strength steel & $2.25 /(1.61+0.077)=1.333$ \\
\hline 2 & Steel $20+$ steel 20 & $2.25 /(4.49+0.21)=0.478$ \\
\hline 3 & Steel $08 \mathrm{kp}+$ steel $08 \mathrm{kp}$ & $2.25 /(8.42+0.4)=0.255$ \\
\hline
\end{tabular}


Table 2. Results of calculations of three models of structures of spherical bottoms

\begin{tabular}{|c|c|c|c|}
\hline Parameter & Model 1 & Model 2 & Model 3 \\
\hline \multicolumn{4}{|c|}{ Admissible stresses in the metal of bottom wall, MPa; $[\sigma]_{\mathrm{op}}=\sigma_{\text {dang }} / n(n=2.7)$} \\
\hline $\begin{array}{l}\text { Inner shell }\left[\sigma_{1}\right] \\
\text { Outer shell }\left[\sigma_{2}\right]\end{array}$ & $\begin{array}{c}74 \\
370.4\end{array}$ & $\begin{array}{l}114.3 \\
114.3\end{array}$ & $\begin{array}{l}74 \\
74\end{array}$ \\
\hline Thickness of the wall of inner shell $S_{1}$, mm & 2.25 & 2.25 & 2.25 \\
\hline \multicolumn{4}{|c|}{ Inner shell } \\
\hline $\begin{array}{l}\text { Inner diameter } d_{\text {in } 1}, \mathrm{~mm} \\
\text { Middle diameter } d_{\text {mid1 }}, \mathrm{mm} \\
\text { Outer diameter } d_{\text {out1 }}, \mathrm{mm}\end{array}$ & $\begin{array}{c}147.5 \\
149.75 \\
152 \\
\end{array}$ & $\begin{array}{c}147.5 \\
149.75 \\
152 \\
\end{array}$ & $\begin{array}{c}147.5 \\
149.75 \\
152 \\
\end{array}$ \\
\hline Thickness of the outer shell wall $S_{2}+C, \mathrm{~mm}$ & 1.687 & 4.7 & 8.82 \\
\hline \multicolumn{4}{|c|}{ Outer shell } \\
\hline $\begin{array}{l}\text { Inner diameter } d_{\text {in } 2}, \mathrm{~mm} \\
\text { Middle diameter } d_{\text {mid2 } 2}, \mathrm{~mm} \\
\text { Outer diameter } d_{\text {out2 } 2}, \mathrm{~mm}\end{array}$ & $\begin{array}{c}152 \\
153.687 \\
155.374\end{array}$ & $\begin{array}{c}152 \\
156.7 \\
161.4\end{array}$ & $\begin{array}{c}152 \\
160.82 \\
169.64\end{array}$ \\
\hline Thickness of the common bottom wall $S=S_{1}+\left(S_{2}+C\right), \mathrm{mm}$ & 3.937 & 6.95 & 11.07 \\
\hline \multicolumn{4}{|c|}{ Common bottom wall } \\
\hline $\begin{array}{l}\text { Inner diameter } d_{\mathrm{in}}, \mathrm{mm} \\
\text { Middle diameter } d_{\text {mid, }}, \mathrm{mm} \\
\text { Outer diameter } d_{\text {out }}, \mathrm{mm}\end{array}$ & $\begin{array}{c}147.5 \\
151.437 \\
155.374 \\
\end{array}$ & $\begin{array}{c}147.5 \\
154.45 \\
161.4 \\
\end{array}$ & $\begin{array}{c}147.5 \\
158.57 \\
169.64 \\
\end{array}$ \\
\hline Ratio $d_{\text {out }} / S$ & 39.465 & 23.22 & 15.324 \\
\hline Ratio $\left(S_{2}+C\right) / S_{1}$ & 0.75 & 2.088 & 3.92 \\
\hline
\end{tabular}

factor $n=2.7$ ) according to the maximum admissible values of the stresses formed in the metal $\sigma_{\mathrm{op}}=\sigma_{\text {dang }} / n$, where $\sigma_{\text {dang }}$ is the critically dangerous stress. Depending on the grade of steel for plastic materials $\sigma_{\text {dang }}=$ $=\sigma_{\mathrm{y}}$, for brittle materials $\sigma_{\text {dang }}=\sigma_{\mathrm{t}}$;

- in the calculation models the strength of welds was taken as equal to the strength of the base metal (for the given calculation mathematical model taking into account the application of different grades of materials, the strength of welds is provided by increasing the total thickness of the common wall on the value of the wall thickness, which in all cases should be not less than $0.5 \mathrm{~mm}$ [7]).

Materials of calculations. On the basis of the carried out calculations (see Table 1) the combination of materials, geometric sizes and ratio of thicknesses $S_{1}$, $S_{2}$ of shells of spherical bottom and of wall thickness
$C$ is shown, where $C$ is determined according to formula [7] for three types of models:

$$
C=\frac{0.05}{1+0.05} S \text {. }
$$

The results of calculations of three models of structures of spherical bottoms are presented in Table 2 .

The values of operating stresses $\sigma_{\mathrm{op} 1} \sigma_{\mathrm{op} 2}, \sigma_{\mathrm{op}}$ which are formed in the metal in the inner and outer shell and in the common wall of the spherical bottom from the applied operating pressure $P_{\mathrm{op}}$, are given in Table 3.

The calculation of stresses, formed in the common wall of the bottom, was carried out the same as for a single-layer material of the total thickness for three types of models. Thus, the strength calculation of welded structure was performed, which in this case is the welded two-layer vessel, where a double-layer

Table 3. Comparison of calculation stresses $\sigma_{\mathrm{op} 1}, \sigma_{\mathrm{op} 2}, \sigma_{\mathrm{op}}$ at $P_{\mathrm{op}}=20 \mathrm{MPa}$ with admissible stresses $\sigma_{1}, \sigma_{2}$ in the metal of inner and outer shells for three models

\begin{tabular}{|c|c|c|c|}
\hline Parameter & Model 1 & Model 2 & Model 3 \\
\hline Admissible stresses $\sigma_{1}, \sigma_{2}, \mathrm{MPa}$ & $\sigma_{1}=74 ; \sigma_{2}=370.4$ & $\sigma_{1}=114.3 ; \sigma_{2}=114.3$ & $\sigma_{1}=74 ; \sigma_{2}=74$ \\
\hline Calculation stresses for inner $\sigma_{\mathrm{op} 1}$, outer $\sigma_{\mathrm{op} 2}$ shells and common bottom wall $\sigma_{\mathrm{op}}, \mathrm{MPa}$ \\
\hline Inner shell $\left(S_{1}\right)$ & $\sigma_{\mathrm{op} 1}=4.447<\sigma_{1}$ & $\sigma_{\mathrm{op} 1}=6.869<\sigma_{1}$ & $\sigma_{\mathrm{op} 1}=4.447<\sigma_{1}$ \\
\hline Outer shell $\left(S_{2}+C\right)$ & $\sigma_{\mathrm{op} 2}=354.2<\sigma_{2}$ & $\sigma_{\mathrm{op} 2}=109.4<\sigma_{2}$ & $\sigma_{\mathrm{op} 2}=70.9<\sigma_{2}$ \\
\hline Common bottom wall $\left(S_{1}+\left(S_{2}+C\right)=S\right)$ & $\sigma_{\mathrm{op}}=192.3<\sigma_{2}$ & $\sigma_{\mathrm{op}}=111.1<\sigma_{1}=\sigma_{2}$ & $\sigma_{\mathrm{op}}=71.6<\sigma_{1}=\sigma_{2}$ \\
\hline
\end{tabular}




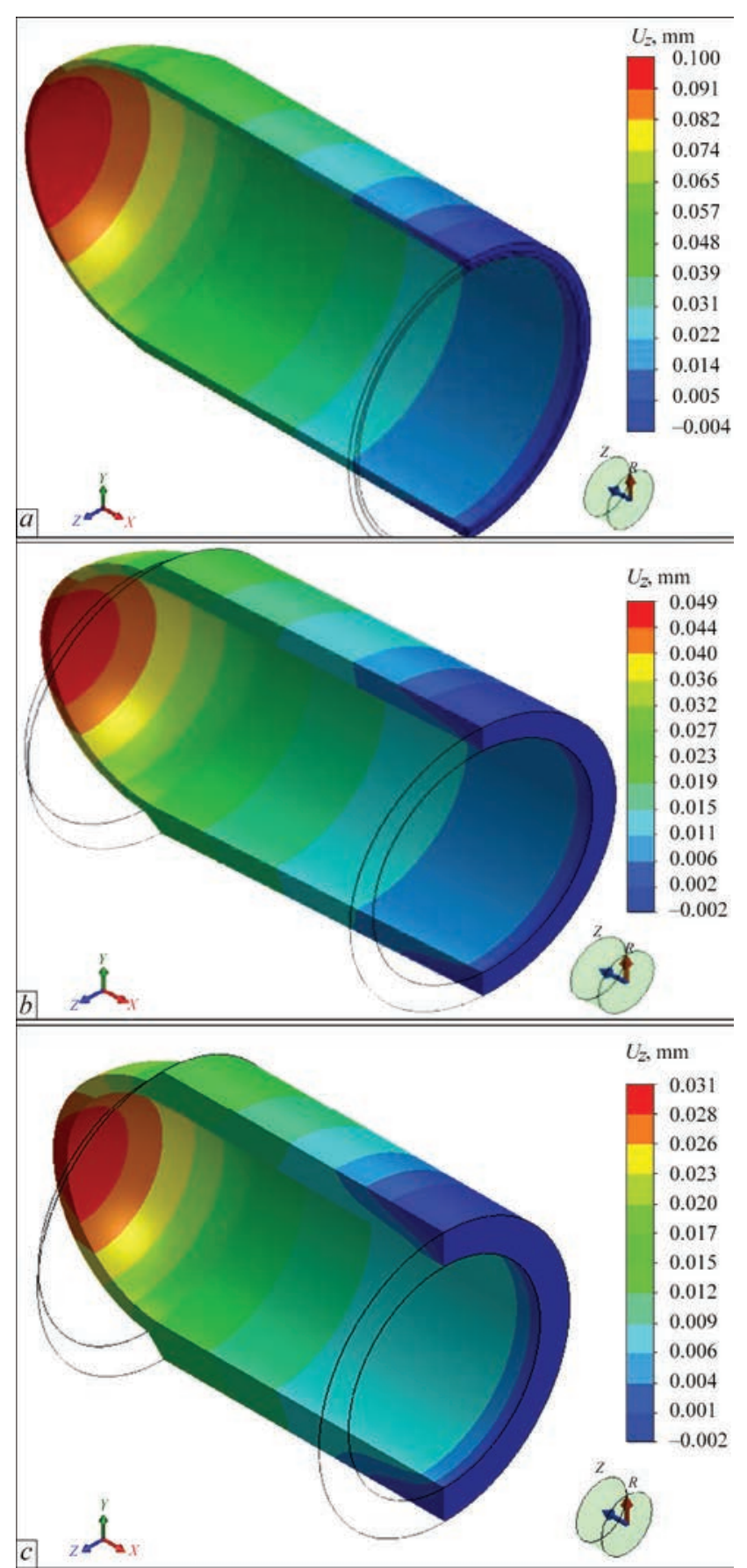

Figure 2. Fields of radial displacements in models $1(a), 2(b)$ and 3 (c) of vessels at their loading by operating pressure

cylindrical body and a spherical bottom are produced also in two-layers [10].

The circumferential stresses and radial displacements obtained as a result of computer simulation are presented in Figures 2 and 3.

The data obtained as a result of computer simulation at the loading by the inner operating pressure of three types of welded structure (welded vessel, in which the cylindrical body and spherical bottom are produced in two-layers) are presented in Table 4. The comparison of values of circumferential stresses (average in thickness), determined as a result of computer simulation, with the stresses, determined according to the analyt-

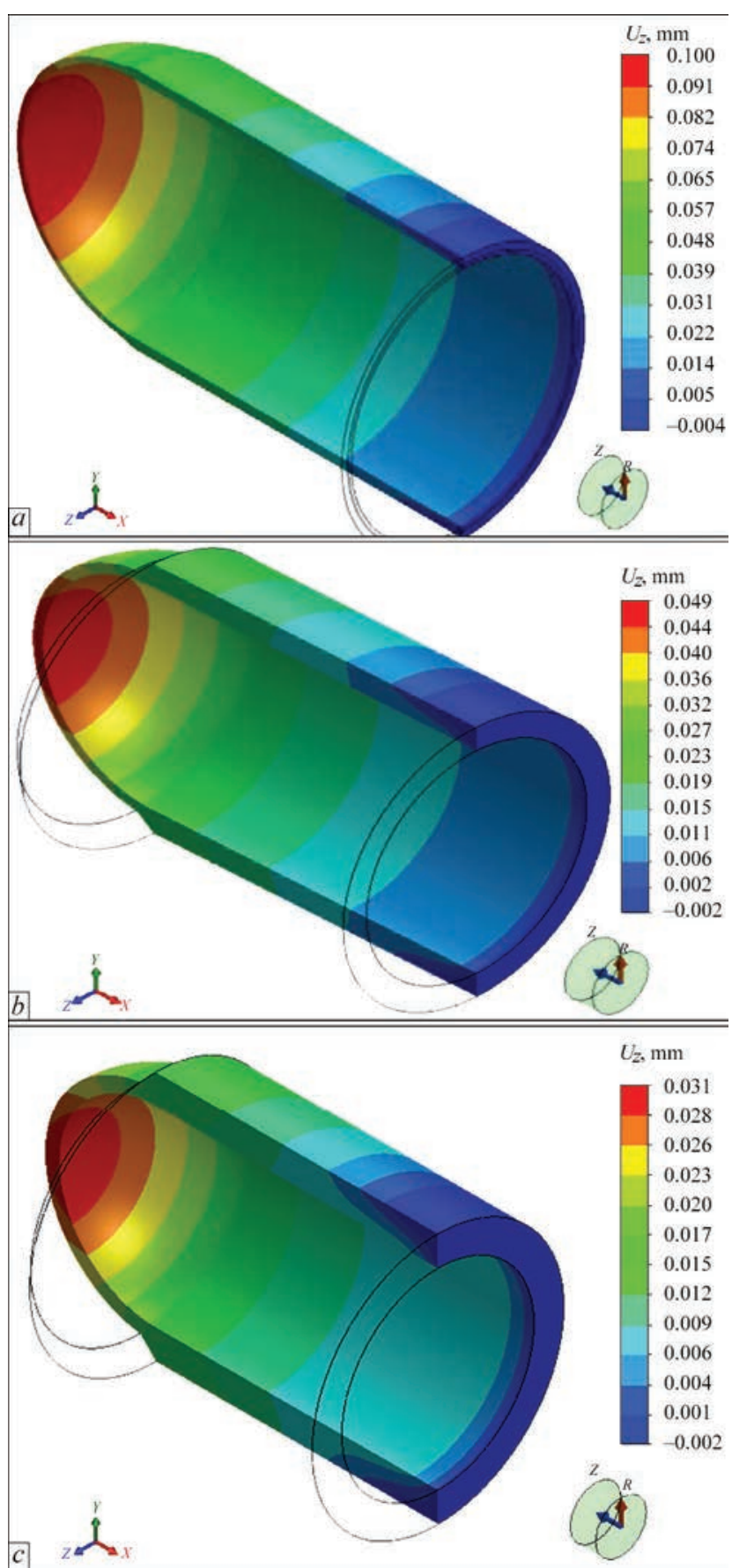

Figure 3. Distribution of circumferential stresses in models $1(a)$, 2 (b) and 3 (c) of vessels at their loading by operating pressure

ical dependences using the calculation method (see Table 3) from applying the operating pressure to the common wall for three models almost coincide or have a slight discrepancy (0.54-3.02\%). The value of stresses, determined by the calculation method, appeared to be higher than the values of stresses, determined as a result of computer simulation.

According to the results of computer simulation it was found that the radial displacements in the common wall of the two-layer shell are increased proportionally to the formed circumferential stresses from model 3 to model 1 and are inversely proportional to the thickness of the common wall of the two-layer shell. 
Table 4. Displacements and stresses at operating pressure loading for models used

\begin{tabular}{|c|c|c|c|}
\hline Parameter & Model 1 & Model 2 & Model 4 \\
\hline Mean value of displacement, $\left.\mathrm{mm}, \Delta_{\mathrm{m}}=\Delta_{\min }+\Delta_{\max }\right) / 2$ & $\Delta_{\mathrm{m}}=0.074$ & $\Delta_{\mathrm{m}}=0.0255$ & $\Delta_{\mathrm{m}}=0.016$ \\
\hline $\begin{array}{l}\text { Mean value of circumferential stresses in common wall of a double-layer shell, MPa } \\
\text { (computer modeling), } \sigma_{\mathrm{m}}=\sigma_{\min }+\sigma_{\max } / 2\end{array}$ & $\sigma_{\mathrm{m}}=190$ & $\sigma_{\mathrm{m}}=110.5$ & $\sigma_{\mathrm{m}}=69.5$ \\
\hline $\begin{array}{l}\text { Mean value of circumferential stresses in common wall of double-layer shell, MPa } \\
\text { (determined by calculations, data of Table } 3 \text { ) }\end{array}$ & $\sigma_{\mathrm{op}}=192.3$ & $\sigma_{\mathrm{op}}=111.1$ & $\sigma_{\mathrm{op}}=71.6$ \\
\hline
\end{tabular}

The largest radial displacements and highest values of circumferential stresses are in model 1 , which has a minimum common thickness of the wall of the two-layer shell. In the thickest common wall of the two-layer shell, in model 3, the values of circumferential stresses are relatively the lowest and the radial displacements in the ranges of strain deformations are the minimum, which corresponds to the Hooke's law. In this case, the optimum thickness of the common wall of the two-layer shell is determined by rational combination of the circumferential stresses and radial displacements in it in the ranges of elastic deformations, basing on the values of strength of the least strength shell material and the strength of the interlayer welded joint. The values of circumferential stresses in the common wall of the two-layer shell, obtained as a result of computer simulation (at the loading by the inner operating pressure of welded structure in the model) are correlated with the circumferential stresses determined previously by the calculation method for all three models.

The values of circumferential stresses determined according to the results of computer simulation and by the calculation method for all three types of models are determined also in accordance with the requirements to the strength of welded joint of shells. In this work according to the results of computer simulation and by the calculation method for all three types of models, the thickness of spherical bottom was determined. However, in accordance with the rules of calculations and designing [7] the wall thickness of the bottom in the real welded structures should be taken as being not smaller than the calculated thickness of the wall of the cylindrical body. For such welded structures as vessels, operating under pressure at the long-term cyclic loading, the minimum radial displacements in the ranges of elastic deformations represent a certain risk. It is predetermined by the possibility of development of fatigue cracks, causing fatigue fracture, including those in the area of interlayer joint.

During designing in order to determine the optimal parameters of a two-layer structure of the bottom, the computer simulation of the stress-strain state at applying the inner operating pressure as well as the inner limiting pressure of the structure is considered to be appropriate aimed at determination and comparison of circumferential stresses obtained during simulation with the stresses, determined by the calculation method according to the analytical dependences.

\section{Conclusions}

1. The rational geometric parameters of the welded two-layer shell were determined using the computer simulation and by the calculation method according to the analytical dependences. For the common wall of the thin-wall two-layer shell the rational combinations of the non-limiting circumferential stresses and radial displacements were specified.

2. During designing the circumferential stresses in the common wall of the shell should be taken into account, the average value of which was determined as a result of computer simulation with the stresses, determined by the calculation method according to the analytical dependences.

1. Konon, Yu.A., Pervukhin, L.B., Chudnovsky, A.D. (1987) Explosion welding. Moscow: Mashinostroenie.

2. Petushkov, V.G. (2005) Application of explosion in welding technique. Kiev: Naukova Dumka.

3. Pismenny, A.S., Novikova, D.P., Prokofiev, A.S. et al. (2004) Properties of weld metal at induction braze-welding of steel 20. The Paton Welding J., 12, 26-32.

4. Pismenny, A.S., Prokofiev, A.S., Pismenny, A.A. et al. (2010) Properties of the welded joints of tubular billets produced by pressure braze-welding with a forming device. Ibid., 7, 22-25.

5. Bakshi, O.I., Shron, R.Z. (1962) Strength in static tension of welded joints with soft interlayer. Svarochn. Proizvodstvo, 5, 6-10.

6. Pismenny, A.A., Gubatyuk, R.S., Prokofiev, A.S. et al. (2014) Braze-welded tubular billets for pipelines and high-pressure vessels. The Paton Welding J., 10, 38-44.

7. Chernega, V.I. (1976) Safe service of vapor boilers, vessels and pipelines. $2^{\text {nd }}$ ed. Kiev: Tekhnika.

8. Pisarenko, G.S., Yakovlev, A.P., Matveev, V.V. (1998) Reference book on strength of materials. $2^{\text {nd }}$ ed. Kiev: Naukova Dumka.

9. Majzel, V.S., Navrotsky, D.I. (1973) Welded structures. Leningrad: Mashinostroenie.

10. Pysmenny, O.S., Savytsky, M.M., Pysmenny, O.O. et al. High-pressure vessel with cylindrical body of shell structure. Pat. 107847 Ukraine. Publ. 25.02.2015. 